\title{
Is host age an important factor in the bionomics of Apanteles myeloenta (Hymenoptera: Braconidae)?
}

\author{
HosSEIN KISHANI FARAHANI and SEYED Hossein GOLDANSAZ
}

Department of Plant Protection, Faculty of Agriculture, University of Tehran, Karaj 3158777871, Iran; e-mail: Kishani@ut.ac.ir

Key words. Hymenoptera, Braconidae, Apanteles myeloenta, Lepidoptera, Pyralidae, Ectomyelois ceratoniae, parasitism, pomegranate, host age

\begin{abstract}
The carob moth, Ectomyelois ceratoniae (Lepidoptera: Pyralidae), is a serious pest and causes a considerable loss of yield of pomegranate in Iran. Apanteles myeloenta (Hymenoptera: Braconidae) is the dominant parasitoid of this pest parasitizing it more than $30 \%$ in recent years. This parasitoid is a candidate for augmentative biological control program to reduce the level of the infestation of fruit overwinter. The objective of this research was to optimize the mass production of $A$. myeloenta. The mean developmental time of females was 28 days and of males 27 days. Pupal development lasted 7 days. The second instar was the preferred host and most heavily parasitized (45\%). Wasps that started their development in second instar hosts produced the highest progeny and those that started in third instar hosts survived as adults for longest. The sex ratio (females to males) of $A$. myeloenta that emerged from carob moth larvae parasitized in the first instar was $1: 3.5$, in the second instar $1: 3$ and in the third instar $1: 2$. The influence of different host ages on the functional response of $A$. myeloenta to host density was assessed. Logistic regression indicated a type II functional response to different densities of all the stages of the host tested.
\end{abstract}

\section{INTRODUCTION}

The carob moth, Ectomyelois ceratoniae (Lepidoptera: Pyralidae), is of Mediterranean origin, but a cosmopolitan pest of pomegranate, pistachio, citrus, date, macadamia and fig crops (Gothilf, 1969, 1978; Alrubeai, 1987; Warner et al., 1990; Shakeri, 1993; Bouka et al., 2000; Mehrnejad, 2002; Nay \& Perring, 2005; Blumberg, 2008). Recently, it was recognized as the most economically damaging pest of pomegranate in Iran, where up to $80 \%$ of the fruit is damaged by this pest and is unmarketable (Shakeri, 2004), and the most economically damaging pest of the high value U.S. date industry, causing $10-40 \%$ loss of yield annually (Warner, 1988; Nay et al., 2006).

Several parasitoids are known to parasitize the carob moth in the Middle East. Eleven species of parasitoids are known to parasitize carob moth larva infesting pomegranate (Kishani Farahani et al., 2011) and 22 species parasitize this pest when infesting carob (Gothilf, 1969). Apanteles myeloenta is one of the most important larval parasitoids of larvae of this pest infesting carob and pomegranate (Gothilf, 1969; Kishani Farahani et al., 2011). This parasitoid reduces the annual loss of yield of pomegranate caused by the carob moth by more than $30 \%$ (Kishani Farahani et al., 2011). According to Kishani Farahani et al. (2012a) A. myeloenta is a solitary, koinobiont (parasitoids whose larvae utilize a growing host), synovigenic (they emerge with some immature eggs and need to feed, to sustain egg production) endoparasitoid of the early instars of the carob moth. When their numbers are boosted by augmentative releases (Jervis et al., 2008; Kishani Farahani et al., 2012 a) it can cause a substantial decrease in the overwintering population of carob moth larvae.

For the immature development of the parasitoid the host is the sole source of nutrients. The evaluation of host quality by female parasitoids is important in host selection, resulting in trade-offs due to variation in host quality and developmental requirements of its offspring (Godfray, 1994; Harvey \& Strand, 2002; Beckage \& Gelman, 2004). The quality of the different stages of the host may differ, so tradeoffs play a key role in host selection (Godfray, 1994; Colinet et al., 2005). These hosts differ in age, body size, behavioral, physiological and immunological status, and thus represent resources of varying qualities and quantities (Chong \& Oetting, 2006). Many studies suggest that host size and age preference by parasitoids affect the adult size and reproductive performance of their progeny (Lampson et al., 1996; Harvey, 2005) and female egg load at emergence (Liu, 1985; Mills \& Kuhlmann, 2000). Host age may also affect sex allocation, percentage parasitism and developmental time of immature parasitoids (Godfray, 1994).

In order to mass rear biological agents for biological control programs it is important to determine the preferred host instar for optimum parasitoid offspring production, a short immature developmental time and an appropriate killing activity and efficiency. Therefore, this study investigated the effects of host age on immature developmental time, offspring sex ratio, percentage parasitism, fecundity, adult longevity and the functional response of $A$. myeloenta. The intention is to use this information to determine the optimal conditions for mass rearing of this parasitoid. 


\section{MATERIAL AND METHODS}

\section{Insect rearing}

Insects were originally collected from the Qom, Ghal-e-Cham region $\left(34^{\circ} 23^{\prime} 31.9^{\prime \prime} \mathrm{N}, 50^{\circ} 36^{\prime} 26.1^{\prime \prime} \mathrm{E}\right)$, Iran. An experimental colony of E. ceratoniae was established on pistachio at $28 \pm$ $1^{\circ} \mathrm{C}, 75 \pm 10 \%$ R.H. and a photoperiod of $16 \mathrm{~L}: 8 \mathrm{D}$. Fifty to 100 one day old $E$. ceratoniae adult moths were released in a large net covered metal cage $(180 \times 30 \times 30 \mathrm{~cm})$ (length : wide : depth) for mating ( 3 days) and ovarian maturation and fed undiluted honey provided in the form of droplets on wax-coated strips of paper, which were replaced daily. Mated females were transferred into small cylindrical net covered plastic cages $(15 \times$ $10 \times 15 \mathrm{~cm})$ and allowed to oviposit on pistachio as described by Ziaaddini et al. (2010). Larvae develop well on pistachio, and this method is commonly used in Iran for the long term culturing of this insect in the laboratory.

To maintain the parasitoid stock culture, 30 mated female wasps were provided with about 900 second instar carob moth larvae for one day and then females were transferred to $250 \mathrm{ml}$ glass beakers, as egg laying units. Parasitized host larvae were reared on pistachio powder until the parasitoids emerged after which the wasps were released in and allowed to mate in a net covered plastic cage. Adult parasitoids were fed on undiluted honey, which was provided in the form of droplets on waxcoated strips of paper. All wasps were maintained and tested under laboratory conditions of $25 \pm 1{ }^{\circ} \mathrm{C}, 50 \pm 10 \%$ R.H. and a photoperiod of $16 \mathrm{~L}: 8 \mathrm{D}$. The adults of $A$. myeloenta used in the experiments were from a laboratory culture that was more than 10 generations old.

\section{Percentage parasitism}

Thirty E. ceratoniae larvae of each host instar, (first, second and third) were exposed to a mated but naïve (never encountered a suitable host before) one-day-old female parasitoid in a cage $(10 \times 15 \times 10 \mathrm{~cm})($ Kishani Farahani et al., 2012 b). After $24 \mathrm{~h}$ exposure, the larvae were removed and reared individually on pistachio. This experiment was replicated 24 times. The number of parasitoids that emerged from the parasitized hosts was recorded in each treatment. Percentage of parasitism was calculated based on the number of wasps that emerged in each tube. Host instars were identified based on the width of the larval head capsule.

\section{Sex ratio}

Thirty carob moth larvae of the first, second and third instars were exposed to a mated but naïve one-day-old female for $24 \mathrm{~h}$ in a cage $(10 \times 15 \times 10 \mathrm{~cm})$. After removing the parasitoid, each group of larvae was reared separately on pistachio nuts and checked daily for parasitoid emergence and the number of males and females was recorded. This experiment was replicated 30 times using naïve one day old mated females.

\section{Immature developmental time}

Thirty E. ceratoniae larvae of each instar (first, second and third) were exposed to a one-day-old mated, naïve female for 24 $\mathrm{h}$ in each replicate. After this period larvae were removed and reared individually on pistachio. The duration of larval and pupal development were recorded. This experiment was replicated 30 times.

\section{Functional response}

In order to determine the functional response of $A$. myeloenta to various host densities, individual wasps were exposed to 13 density levels $(2,4,6,8,10,15,20,25,30,35,40,45$ and 50) of E. ceratoniae larvae of each instar. For each host density, larvae were placed in a glass tube (diameter: $7 \mathrm{~cm}$, height: 20 $\mathrm{cm}$ ) and provided with pistachio. A single, 1-d-old mated, naive female wasp was introduced into each glass tube and provided with streaks of $20 \%$ honey solution. Twenty five replicates for larval density levels of $2,4,6,8,10,15,20$ and twenty replicates for other densities were used. The glass tubes were kept in controlled growth chambers at $25 \pm 1{ }^{\circ} \mathrm{C}, 50 \pm 10 \%$ R.H. and a photoperiod of $16 \mathrm{~L}: 8 \mathrm{D}$. After $24 \mathrm{~h}$, the wasps were removed from the glass tubes. Percentage of parasitism was calculated based on the number of wasps that emerged in each tube. Greater replication of the lowest host densities was needed to obtain a more accurate description of the initial part of functional response curve.

\section{Parasitoid fecundity}

To study the effects of immature developmental quality on the fecundity of the adult parasitoids they were kept in thirty cages under the same rearing condition as described above. Each cage contained one pair of newly emerged male and female wasps which had been reared on a particular host stage and provided daily with droplets of honey and water (provided separately). In each cage 30 host larvae (second instar) were exposed to the females. The host larvae were replaced daily by the same number and instar of larvae until the female died. The number of adult parasitoids that emerged from the parasitized hosts was recorded.

\section{Adult longevity}

Adult longevity of mated female parasitoids in the presence of hosts was assessed. Thirty wasp cocoons were randomly selected from the insect colonies and placed in an oviposition cage. The cage was checked once a day for adults that had emerged during the previous $24-\mathrm{h}$ period and all non-emerged pupae were removed to provide a uniform emergence date for the test insects. Males and females were kept together for $24 \mathrm{~h}$ to ensure mating occurred. Mated females in the oviposition cage were provided with honey and water. Thereafter the number of live $A$. myeloenta females was recorded daily. Thirty wasps were randomly assigned to each treatment.

\section{Statistical analysis}

The normality in the distributions of the variation in the data on A. myeloenta immature developmental time, adult longevity, fecundity and host age preference were tested using the Kolmogorov-Smirnov test. As it was normally distributed, no transformation was needed and the data are presented as means $( \pm$ SEM) per treatment. Treatment effects were analyzed using analysis of variance (ANOVA), with treatment means separated using Tukey's HSD test at $\mathrm{P}<0.05$. Data analysis for functional responses includes two steps (Juliano, 2001). The first step in analyzing the data is to determine whether the functional response is type II or type III. The most effective way to distinguish type II and III functional responses involves logistic regression of proportion of parasitized hosts versus number of hosts exposed to parasitization (Juliano, 2001).

The following polynomial function (1) was fitted to the data (Juliano, 2001).

$$
\frac{N_{a}}{N_{0}}=\frac{\exp \left(P_{0}+P_{1} N_{0}+P_{2} N_{0}^{2}+P_{3} N_{0}^{3}\right)}{1+\exp \left(P_{0}+P_{1} N_{0}+P_{2} N_{0}^{2}+P_{3} N_{0}^{3}\right)}
$$

where $P_{0}, P_{1}, P_{2}$ and $P_{3}$ are parameters to be estimated, $N_{a}$ is the number of parasitized larvae and $N_{0}$ is the initial host density. These parameters were estimated using the CATMOD procedure in SAS software (SAS Institute, 2003). The sign of $P_{1}$ and $P_{2}$ can be used to distinguish the shape of curves. A positive linear parameter $\left(P_{1}\right)$ and a negative quadratic parameter $\left(P_{2}\right)$ indicate that the functional response is type III, whereas if both parameters are negative, the functional response is type II (Juli- 
ano, 2001; Allahyari et al., 2004). After determining the type of functional response, the parameters handling time $\left(T_{h}\right)$ and attack constant $(a)$ were estimated. For this purpose we used nonlinear least square regression (NLIN procedure with DUD method in SAS). At first, the random parasite equation (2) was used to fit the data:

$$
N_{a}=N_{0}\left[1-\exp \left(\frac{a T_{t}}{1+a T_{h} N_{0}}\right)\right]
$$

where $a$ is the attack constant (or instantaneous searching rate), $T_{t}$ the time of exposure, and $T_{h}$ the handling time.

\section{RESULTS}

The immature development time of female wasps was $30.2 \pm 0.34,27.8 \pm 0.44$ and $28.1 \pm 0.47$ days in L1, L2 and L3 hosts, respectively, whilst males required $31.1 \pm$ $0.51 \mathrm{~d}, 27.3 \pm 0.3 \mathrm{~d}$ and $28.1 \pm 0.24$ days. Developmental time (from egg to pupa and pupal duration) of $A$. myeloenta differed significantly in the different larval instars of the host $\left(\mathrm{P}<0.0001, \mathrm{~F}_{2,87}=15.49\right)$ (Table 1).

Offspring sex ratio of $A$. myeloenta that emerged from first, second, and third instar old carob moth larvae, was 1 : 3.5 (females : males), $1: 3$ and $1: 2$, respectively. These results indicate that proportionally fewer males emerged from the older host larvae. The total numbers of adults that emerged from first, second and third instar larvae of the host was 153, 526 and 378, respectively.

Our results indicate that significantly different percentages of the three different host instars were parasitized $\left(\mathrm{P}<0.0001, \mathrm{~F}_{2,87}=3724.24\right)$ (Table 1). Of the host larvae the second instar was the most heavily parasitized (45.1 \pm $0.3 \%$ ).

There were significant differences in the fecundity of three groups of adults studied $\left(\mathrm{P}<0.0001, \mathrm{~F}_{2,87}=28.87\right)$. The lowest fecundity was recorded for wasps reared on first instar larvae (Table 1). The mean daily fecundity was 5.54, 5.32 and 5.03 eggs for wasps reared on first, second and third instar host larvae, respectively.

Adult wasps reared on different host instars differed significantly in longevity $\left(\mathrm{P}<0.0001, \mathrm{~F}_{2,87}=61.08\right)$. The wasps that lived longest developed in third instar larvae of the host (Table 1)

Results of the logistic regression analysis revealed that the number of $E$. ceratoniae larvae parasitized by $A$. myeloenta was a function of host density and indicated a type
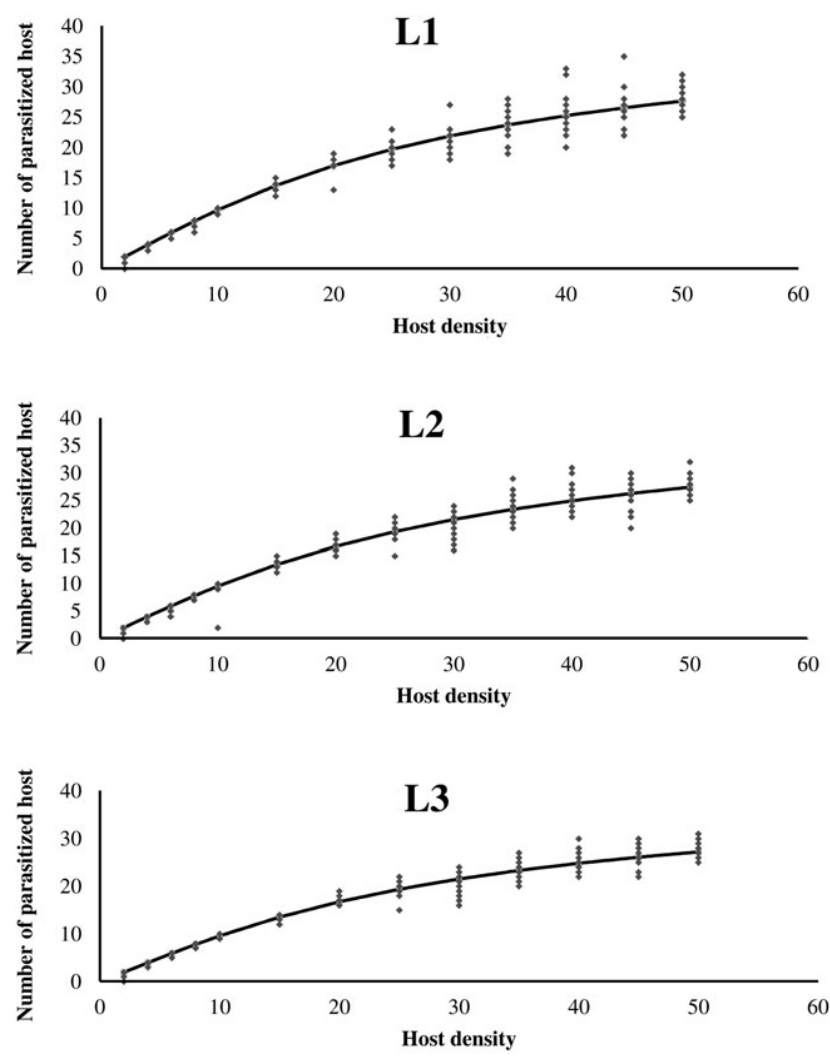

Fig. 1. Functional responses of A. myeloenta to different densities and instars of larvae of its host, the carob moth.

II functional response (Fig. 1). In all cases, the linear term of the polynomial regression of the percentage of carob moth larvae parasitized versus initial density was negative (Table 2). Handling times $\left(T_{h}\right)$ and attack rates $(a)$ of $A$. myeloenta on different host instars are given in Table 3. The maximum percentage of hosts parasitized is limited by an upper asymptote defined by the ratio $T / T_{h}$ (Hassell, 1978). Our results indicate that the maximum percentage of first, second and third instar hosts parasitized by $A$. myeloenta was $47.9 \%, 42.7 \%$ and $41.5 \%$, respectively.

\section{DISCUSSION}

The results presented indicate that the bionomics of $A$. myeloenta are affected by the age of the host when parasi-

TABLE 1. Duration of development of the immature stages of females and males of $A$. myeloenta that developed in different larval instars of the host (L1, L2 and L3) and the percentage parasitism, adult longevity and fecundity recorded for the adults that emerged from the different larval instars of the host.

\begin{tabular}{|c|c|c|c|c|c|c|c|}
\hline \multirow{4}{*}{$\begin{array}{l}\text { Immature } \\
\text { developmental } \\
\text { time }\end{array}$} & \multicolumn{4}{|c|}{ Female } & \multicolumn{3}{|c|}{ Male } \\
\hline & \multicolumn{2}{|r|}{ L1 } & $\mathrm{L} 2$ & L3 & L1 & L2 & L3 \\
\hline & Egg to pupa period & $10.2 \pm 0.2^{\mathrm{a} *}$ & $9 \pm 0.22^{b}$ & $7.5 \pm 0.25^{\mathrm{c}}$ & $10.6 \pm 0.3^{\mathrm{a}}$ & $9.8 \pm 0.16^{\mathrm{b}}$ & $8.8 \pm 0.2^{c}$ \\
\hline & Pupal duration & $19.9 \pm 0.21^{\mathrm{a}}$ & $18.8 \pm 0.42^{\mathrm{b}}$ & $14.6 \pm 0.28^{c}$ & $20.5 \pm 0.3^{\mathrm{a}}$ & $18.5 \pm 0.23^{b}$ & $18.3 \pm 0.2^{\mathrm{b}}$ \\
\hline & & \multicolumn{6}{|c|}{ Host age } \\
\hline & & \multicolumn{2}{|c|}{ L1 } & \multicolumn{2}{|c|}{$\mathrm{L} 2$} & \multicolumn{2}{|c|}{ L3 } \\
\hline \multicolumn{2}{|c|}{ Percentage parasitism } & \multicolumn{2}{|c|}{$31.7 \pm 0.1^{\mathrm{b}}$} & \multicolumn{2}{|c|}{$45.10 \pm 0.31^{\mathrm{a}^{*}}$} & \multicolumn{2}{|c|}{$20.40 \pm 0.11^{\mathrm{c}}$} \\
\hline Fecundity & & \multicolumn{2}{|c|}{$71.5 \pm 2.9^{\mathrm{b}}$} & \multicolumn{2}{|c|}{$93.5 \pm 1.3^{\mathrm{a}}$} & \multicolumn{2}{|c|}{$93.06 \pm 2.4^{\mathrm{a}}$} \\
\hline Longevity & & \multicolumn{2}{|c|}{$12.9 \pm 0.4^{b}$} & \multicolumn{2}{|c|}{$17.5 \pm 0.1^{\mathrm{a}}$} & \multicolumn{2}{|c|}{$18.4 \pm 0.4^{\mathrm{a}}$} \\
\hline
\end{tabular}

*Indicate significant differences $(\mathrm{P}=0.05)$ following post hoc separation of means using Tukey tests. 
TABLE 2. Results of logistic regression analysis of the proportion of different densities of three different instar E. ceratoniae larvae parasitized by A. myeloenta.

\begin{tabular}{|c|c|c|c|c|c|}
\hline Host instar & Parameter & Estimate & SE & $\times 2$-value & P-value \\
\hline \multirow{4}{*}{ L1 } & Constant & 4.7921 & 0.4586 & 109.18 & $<0.0001$ \\
\hline & Linear & -0.2173 & 0.0507 & 18.36 & $<0.0001$ \\
\hline & Quadratic & 0.00368 & 0.00173 & 4.52 & 0.0334 \\
\hline & Cubic & -0.00002 & 0.000018 & 1.64 & 0.2005 \\
\hline \multirow{4}{*}{ L2 } & Constant & 5.3548 & 0.5103 & 110.11 & $<0.0001$ \\
\hline & Linear & -0.2651 & 0.0550 & 23.22 & $<0.0001$ \\
\hline & Quadratic & 0.00448 & 0.00148 & 7.01 & 0.0081 \\
\hline & Cubic & -0.00003 & 0.000019 & 2.90 & 0.0884 \\
\hline \multirow{4}{*}{ L3 } & Constant & 3.4953 & 0.3581 & 95.27 & $<0.0001$ \\
\hline & Linear & -0.0945 & 0.0423 & 5.00 & 0.0253 \\
\hline & Quadratic & 0.000049 & 0.00150 & 0.00 & 0.9743 \\
\hline & Cubic & 0.000011 & 0.000016 & 0.43 & 0.5139 \\
\hline
\end{tabular}

tized. In addition, the results indicate that this parasitoid preferred to oviposit in second and third instar larvae of the host, which results in larger offspring being produced in a shorter time. For A. myeloenta, the quality and amount of food available for its offspring is dependent on the age of the host parasitized. The adults that developed in older hosts took less time to complete their development, were more fecund and survived for longer.

As our results reveal the developmental time of this parasitoid was longer in small than in large hosts. Both females and males took more time to complete their immature development in small hosts. According to Harvey et al. (2000) development time of A. carpatus is much longer in small than large hosts and there is a lag phase in their development when in small hosts. In early instars of its host, the larval development of $A$. myeloenta is delayed. The host larva provides the nutrients for parasitoid development (Smilowitz \& Iwantsch, 1973; Hebert \& Cloutier, 1990; Harvey \& Strand, 2002; Harvey et al., 2004). Therefore, the developmental strategy adopted by the larvae of this parasitoid developing in nutritionally suboptimal small or early instar hosts is to optimize the trade-off between development time and size. This suggests that there is a critical host body size (or age) that must be attained for the successful completion of the development of the parasitoid.

Our results indicate that age of carob moth larvae is a critical factor affecting the sex ratio of the offspring of $A$. myeloenta. There is a correlation between the sex ratio of species of solitary koinobiont parasitoids and the sizes of their hosts (Charnov et al., 1981; King, 1993; Sequeira \& Mackauer, 1993; Ueno \& Tanaka, 1997; Ode \& Heinz, 2002). The general trend is that proportionally more female wasps emerge from large than small hosts. Host age is another factor that significantly affects the parasitoid sex ratio (King, 1987; Godfray, 1994). The sex ratio of parasitoid wasps is commonly affected by the amount of food available for their developing larvae (Charnov et al., 1981; King, 1993; Ueno \& Tanaka, 1997). Large carob moth larvae provide more resources for $A$. myeloenta larvae and thus more female offspring emerge from large hosts.

According to our results, second instar host larvae were the most frequently parasitized. Al-Maliky \& Al-Izzi (1986) state that 2-3 day old carob moth larvae are the preferred host and the most suitable for rearing an unidentified Apanteles species are 7 day-old larvae. Large hosts appear to be better hosts for parasitoids so the expectation is that parasitoids should prefer to parasitize large hosts but large larvae can actively defend themselves against attacks from parasitoids by shaking their body and are not therefore, easy to parasitize. Other characteristics such as physiological immunity may also determine whether the parasitoid can complete its development. So in order to optimize oviposition success parasitoids prefer to oviposit in hosts of a specific size (Drost et al., 2000).

TABLE 3. Parameters estimated using Rogers's equation, which measure the response of $A$. myeloenta to different densities and different instars of E. ceratoniae larvae.

\begin{tabular}{lccccc}
\hline \multirow{2}{*}{ Host instar } & Parameter & Estimate & \multirow{2}{*}{ SE } & Asymptotic 95\% CI \\
\hline \multirow{2}{*}{ L1 } & $a$ & 0.6297 & 0.2846 & 0.0696 & Upper \\
\hline \multirow{2}{*}{ L2 } & $T_{h}$ & 0.5788 & 0.0177 & 0.5439 & 0.1897 \\
\hline \multirow{2}{*}{ L3 } & $a$ & 0.6328 & 0.2564 & 0.1281 & 1.1375 \\
& $T_{h}$ & 0.5787 & 0.0178 & 0.5438 & 0.6136 \\
\hline
\end{tabular}


According to our results the fecundity of $A$. myeloenta is dependent of the age of the host. Lopez et al. (2009) state that host body size influenced the life expectancy of Diachasmimorpha longicaudata (Hymenoptera: Braconidae) as starved females and males of this species that emerged from large hosts lived longest. Host body size also affected gross and net fecundity of this parasitoid as the females that emerged from medium and large host larvae were the most fecund. The oviposition period was not affected by the body size of females, but body size did affect fecundity, with the medium and large females were more fecund than small females. According to our results female fecundity was affected by host age as the most fecund wasps emerged from third instar host larvae, which are bigger than those of the other two other instars. In female parasitoids, fecundity is often correlated with its body size and quality of the food available to the parasitoid during its development (King, 1989; Jervis et al., 2008). This relationship is particularly marked in proovigenic species, where the maximum number of eggs an individual female can lay is dependent on their nutrient reserves, which are obtained by the larvae (Ueno, 1999). In synovigenic species, egg production is also dependent on the amount of food available for adult females (Jervis \& Kidd, 1986; Heimpel \& Collier, 1996) and therefore, in this case body size is not always a good indicator of female fecundity (Ueno, 1999). However, several studies also show that there is a positive correlation between body size and female fecundity in synovigenic parasitoids (Godfray, 1994).

The $A$. myeloenta adults that developed in large hosts lived the longest. Several studies report a relationship between host size and parasitoid survival (Tillman \& Cate, 1993; Jervis \& Copland, 1996; Sagarra et al., 2001). In parasitoids, as well as other insects, large adult body size is often related with increased resource carry-over from the larval stage, and this is manifested in higher energy reserves (Riviero \& West, 2002; Ellers \& Jervis, 2003). Our results also indicate that host age affects adult survival because large hosts provide more resources for the larval stages of the parasitoid.

A type II functional response is frequently reported in insects (Hassel et al., 1977; Begon et al., 1996). In more than three-quarters of the studies a type II and in less than one-fifth a type III functional response is recorded for insect parasitoids (Fernandez-Arhex \& Corley, 2003). According to Matadha et al. (2005) host age can affect the type and parameters of functional responses. Bellows (1985) states that search rates and handling times are also dependent on the instars of the host available for attack in the case of Lariophagus distinguendus Förster (Hymenoptera: Pteromalidae) and the search rates are higher and handling times lower for large instar hosts. In our study, attack rate and handling time of third instar hosts were lower than for younger instars but the attack rate was similar for second and first instar hosts but lower for first than second instar hosts. Godfray (1994) suggests that large hosts are more able to defend themselves. This may be due to the frequent kicking and shaking by large hosts.
The thicker cuticle of large hosts probably makes it harder for parasitoids to insert their ovipositors and oviposit, which may result in a longer handling time.

\section{CONCLUSION}

As our results revealed that rearing A. myeloenta on second and third instar hosts can result in the production of more female offspring, higher percentage parasitism and short immature developmental time. This indicates that if the objective is to maximize the production parasitoids they should be reared on large hosts. The results obtained further our understanding of the parasitoid-host interaction. This information will be used to optimize laboratory-rearing procedures for $A$. myeloenta and improve augmentation programs using this parasitoid by refining decisions about releases in order to achieve higher levels of parasitism. However, studies are now required at the field scale of the effectiveness of parasitoids that have emerged from hosts of different ages.

ACKNOWLEDGEMENTS. We appreciated the assistance of A. Zibaee and M. Eslamizad and the help with the language and writing and scientific guidance provided by M.M. Ramadan of Hawaii University. We also thank C. Van Achterberg, Natural History Museum of Netherland for his help with identifying the parasitoid. This study was financially supported by the University of Tehran but the sponsor was not in any way involved with the design of this study, collection, analysis and interpretation of data, writing of the report and the decision to submit the paper for publication.

\section{REFERENCES}

Allahyari H., Fard P.A. \& Nozari J. 2004: Effects of host on functional response of offspring in two populations of Trissolcus grandis on the sunn pest. - J. Appl. Entomol. 128: $39-43$.

Al-Maliky S.K. \& Al-Izzi M.A.J. 1986: Parasites of Ectomyelois ceratoniae with biological studies on Apanteles sp. Group Ultor in Iraq. - Entomophaga 31: 313-319.

Alrubeal H.F. 1987: Growth and development of Ectomyelois ceratoniae (Lepidoptera: Pyralidae). - J. Stor. Prod. Res. 23: 133-135.

Beckage N.E. \& Gelman D.B. 2004: Wasp parasitoid disruption of host development: implications for new biologically based strategies for insect control. - Annu. Rev. Entomol. 49: 299-330.

Begon M., Harper J.L. \& Townsend C.R. 1996: Ecology: Individuals, Populations, Communities. 3rd ed. Blackwell Scientific Publications, Oxford, $1068 \mathrm{pp}$.

BelLows T.R. 1985: Effects of host and parasitoid age on search behavior and oviposition rates in Lariophagus distinguendus Förster (Hymenoptera: Pteromalidae). - Res. Popul. Ecol. 27: $65-76$.

Blumberg D. 2008: Date palm arthropod pests and their management in Israel. - Phytoparasitica 36: 411-448.

Bouka H., Chemseddine M., Abbassi M. \& Brun J. 2000: La pyrale des dattes dans la région de Tafilalet au Sud-Est du Maroc. - Fruits 56: 189-196.

Charnov E.L., Hartogh R.L., Los-den Jones W.T. \& van den Assem J. 1981: Sex ratio evolution in a variable environment. - Nature 289: 27-33.

Chong J.H. \& Oetting R.D. 2006: Host stage selection of the mealy bug parasitoid Anagyrus spec. nov near sinope. Entomol. Exp. Appl. 121: 39-50. 
Colinet H., Salin C., Boivin G. \& Hance T. 2005: Host age and fitness-related traits in a koinobiont aphid parasitoid. - Ecol. Entomol. 30: 473-479.

Drost Y.C., Qiu Y.T., Posthuma-Doodeman C.J.A.M. \& van LENTEREN J.C. 2000: Comparison of searching strategies of five parasitoid species of Bemisia argentifolii. - J. Appl. Entomol. 124: 105-112.

LENTEREN J.C. 2000: Comparison of searching strategies of five parasitoid species of Bemisia argentifolii. - J. Appl. Entomol. 124: 105-112.

Ellers J. \& Jervis M. 2003: Body size and the time of egg production in parasitoid wasps. - Oikos 102: 164-172.

Fernandes-Arhex V. \& Corley J. 2003: The functional response of parasitoids and its implications for biological control. - Biocontr. Sci. Tech. 13: 403-413.

Godfray H.C.J. 1994: Parasitoids: Behavioral and Evolutionary Ecology. Princeton University Press, Princeton, NJ, $473 \mathrm{pp}$.

GothiLF S. 1978: Establishment of the imported parasite Pentalitomastix plethoricus (Hym.: Encyrtidae), on Ectomyelois ceratoniae (Lep.: Phycitidae) in Israel. - Entomophaga 23: 299-302.

GoтнiLf S. 1969: Natural enemies of the carob moth Ectomyelois ceratoniae. - Entomophaga 14: 195-202.

HaRveY J.A. 2005: Factors affecting the evolution of development strategies in parasitoid wasps: the importance of functional constraints and incorporating complexity. - Entomol. Exp. Appl. 117: 1-13.

Harvey J.A. \& Strand M.R. 2002: The developmental strategies of endoparasitoid wasps vary with host feeding. Ecology 83: 2439-2451.

Harvey J.A., Kadash K. \& Strand M.R. 2000: Differences in larval feeding behavior correlate with altered developmental strategies in two parasitic wasps: implications for the sizefitness hypothesis. - Oikos 88: 621-629.

Harvey J.A., Bezemer T.M., Elzinga J.A. \& Strand M.R. 2004: Development of the solitary endoparasitoid Microplitis demolitor: host quality does not increase with host age and size. Ecol. Entomol. 29: 35-43.

Hassel M.P. 1978: The Dynamics of Arthropod Predator-Prey Systems. Princeton University Press, Princeton, NJ, 248 pp.

Hassel M.P., Lawton J.H. \& Beddington J.R. 1977: Sigmoid functional responses by invertebrate predators and parasitoids. - J. Anim. Ecol. 46: 249-262.

Heimpel G.E. \& Collier T.R. 1996: The evolution of hostfeeding behaviour in insect parasitoids. - Biol. Rev. 71: $373-400$

Herbert C. \& Cloutier C. 1990: Host instar as a determinant of preference and suitability for two parasitoids attacking late instars of the spruce budworm (Lepidoptera: Tortricidae). Ann. Entomol. Soc. Am. 83: 734-741.

JERvis M.A. \& KidD N.A.C. 1986: Host-feeding strategies in hymenopteran parasitoids. - Biol. Rev. 61: 395-434.

Jervis M.A. \& Coplant M.J.W. 1996: The life cycle. In Jervis M.A. \& Kidd N.A.C. (eds): Insect Natural Enemies: Practical Approaches to their Study and Evaluation. Chapman \& Hall, London, pp. 63-160.

Jervis M.A., Ellers J. \& Harvey J.A. 2008: Resource acquisition, allocation, and utilization in parasitoid reproductive strategies. - Annu. Rev. Entomol. 53: 361-385.

Juliano S.A. 2001: Nonlinear curve fitting: Predation and functional response curves. In Scheiner S.M. \& Gurevitch J. (eds): Design and Analysis of Ecological Experiments. Chapman and Hall, New York, pp. 178-196.

KING B.H. 1987: Offspring sex ratios in parasitoid wasp. Quart. Rev. Biol. 62: 367-396.
KING B.H. 1989: Host-size-dependent sex ratios among parasitoid wasp: does host growth matter? Oecología 78: 420-426.

KING B.H. 1993: Sex ratio manipulation by the parasitoid wasps. In Wrensch D.L. \& Ebbert M. (eds): Evolution and Diversity of Sex Ratio in Insects and Mites. Chapman and Hall, New York, pp. 418-441.

Kishani Farahani H., Goldansaz S.H., Sabahi Q. \& ShaKeri M. 2011: A study on the larval parasitoids of carob moth, Ectomyelois ceratoniae in Varamin, Qom and Saveh. J. Iran. Plant Prot. Sci. 41: 337-344.

Kishani-Farahani H., Goldansaz S.H. \& Sabahi Q. 2012a: A survey on the over-wintering larval parasitoids of Ectomyelois ceratoniae in three regions in Iran. - Crop Prot. 36: 52-57.

Kishani Farahani H., Bell H. \& Goldansaz S.H. 2012b: Biology of Apanteles myeloenta (Hymenoptera: Braconidae), a larval parasitoid of carob moth Ectomyelois ceratoniae (Lepidoptera: Pyralidae). - J. Asia-Pac. Entomol. 15: 607-610.

LAMPSON L.J., MorSE J.G. \& LuCK R.F. 1996: Host selection, sex allocation, and host feeding by Metaphycus helvolus (Hymenoptera: Encyrtidae) on Saissetia oleae (Homoptera: Coccidae) and its effect on parasitoid size, sex, and quality. -Env. Entomol. 25: 283-294.

LiU S.S. 1985: Aspects of the numerical and functional responses of the aphid parasite, Aphidius sonchi, in the laboratory. - Entomol. Exp. Appl. 37: 247-256.

Lopez O.P., Hénaut Y., Cacino J., Lambin M., Cruz-López L. \& RoJAS J.C. 2009: Is host size an indicator of quality in the mass-reared parasitoid Diachasmimorpha longicaudata (Hymenoptera: Braconidae)? - Fla Entomol. 92: 441-449.

Matadha D., Hamilton G.C., Lashomb J.H. \& Zhang J. 2005: Ovipositional preferences and functional response of parasitoids of euonymus scale, Unaspis euonymi (Comstock) and San Jose scale, Quadraspidiotus perniciosus (Comstock) (Homoptera: Diaspididae). - BioControl 32: 337-347.

Mehrnejad M. 2002: Biology of carob moth, E. ceratoniae new pest on pistachio in Rafsanjan. - App. Entomol. Phytopath. 60: $1-11$.

Mills N.J. \& Kuhlmann U. 2000: The relationship between egg load and fecundity among Trichogramma parasitoids. Ecol. Entomol. 25: 315-324.

NAY J.E. \& Perring T.M. 2005: Impact of ant predation and heat on carob moth (Lepidoptera: Pyralidae) mortality in California date gardens. - J. Econ. Entomol. 98: 725-731.

NAY J.E., Boyd E.A. \& Perring T.M. 2006: Reduction of carob moth in "deglet noor" dates using a bunch cleaning tool. Crop Prot. 25: 758-762.

Ode P.J. \& Heinz K.M. 2002: Host size dependent sex ratio theory and improving mass reared parasitoid sex ratios. BioControl 24: 31-41.

Riviero A. \& West S.A. 2002: The physiological cost of being small in a parasitic wasp. - Evol. Ecol. Res. 4: 407-420.

Sagarra L.A., Vincent C. \& Stewart R.K. 2001: Body size as an indicator of parasitoid quality in male and female Anagyrus kamali (Hymenoptera: Encyrtidae). - Bull. Entomol. Res. 91: 363-367.

SAS Institute 2003: SAS User's Guide: Statistics, Version 9.1. SAS Institute, Cary, NC.

Sequeira R. \& Mackauer M. 1993: Seasonal variation in body size and offspring sex ratio in field populations of the parasitoid wasp, Aphidius ervi (Hymenoptera: Aphidiidae). Oikos 68: 340-346.

SHAKERI M. 1993: First report of attack of Spectrobates ceratoniae Zell. to figs in Iran. - Appl. Entomol. Phytopathol. 60: 29. 
SHAKERI M. 2004: A review on investigations on pomegranate neck worm in Iran. In: A Proceeding on Evaluation of Finding and Current Problems Associated with Spectrobates ceratoniae Management in Pomegranate. Ministry of Jihad-eAgriculture, Organization of Research and Education. Report no. $14 / 1383 /$ bju, 33 pp.

Smilowitz Z. \& IwanTsch G.F. 1973: Relationships between the parasitoid Hyposoter exiguae and the cabbage looper Trichoplusia ni: effects of host age on developmental rate of the parasitoid. - Environ. Entomol. 2: 759-763.

Tillman P.G. \& CAte J.R. 1993: Effect of host size on adult size and sex ratio of Bracon mellitor (Hymenoptera: Braconidae). - Environ. Entomol. 22: 1161-1165.

Ueno T. 1999: Host size dependent sex ratio in a parasitoid wasp. - Res. Popul. Ecol. 41: 47-57.

UENo T. \& TANAKA T. 1997: Comparison of primary and secondary sex ratios in parasitoid wasps using a method for observing chromosomes. - Entomol. Exp. Appl. 82: 445-452.

Warner R.L. 1988: Contribution to the Biology and the Management of the Carob Moth, Ectomyelois ceratoniae (Zeller) in "Deglet Noor" Date Gardens in the Coachella Valley of California. Ph.D. Dissertation, University of California, Riverside.

Warner R.L., Barnes M.M., Laird E.F. \& Lanham M.D. 1990: Chemical control of carob moth, Ectomyelois ceratoniae (Lepidoptera: Pyralidae), and various nitidulid beetles (Coleoptera) on "Deglet Noor" dates in California. - J. Econ. Entomol. 83: 2357-2361.

ZiaAddini M., Goldansaz S.H., Ashouri A. \& Ghasempor A.R. 2010: A comparison of the calling behavior and some biological characters of three different geographic populations of Ectomyelois ceratoniae under laboratory conditions. - $J$. Iran. Plant Prot. Sci. 41: 81-93.

Received July 2, 2012; revised and accepted November 7, 2012 